\title{
PRICE ELASTICITY OF SUPPLY OF BOTTLED QUALITY WHITE WINE IN THE CZECH REPUBLIC
}

\author{
Pavel SYROVÁTKA ${ }^{1 *}$, Pavel ŽUFAN ${ }^{2}$
}

\author{
Address: \\ ${ }^{1}$ Mendel University in Brno, Faculty of Business and Economics, Department of Economics, Zemědělská 1, 61300 Brno, Czech Republic, phone: \\ +420545132556 \\ ${ }^{2}$ Mendel University in Brno, Faculty of Business and Economics, Department of Management, Zemědělská 1, 61300 Brno, Czech Republic. \\ *Corresponding author: pavels@mendelu.cz
}

\section{ABSTRACT}

This paper is focused on the supply of the Czech producers of bottled quality white wine. Namely, a dependence of their sales of this wine category on the market price of bottled quality white wine was examined. Monthly data from the CZSO and SZIF database, years 2004-2012, were used for the price-supply analysis. Price-supply reactions of the Czech wine producers were investigated through two-stage cointegration method developed by Engle and Granger. Short-term and long-term price elasticity of studied market supply was based on the error correction model designed and statistically verified by the authors.

Keywords: Czech wine market, market supply, quality white wine, price-supply cointegration, error correction model, price-supply elasticity

JEL: L21, M21, Q11

\section{INTRODUCTION}

Evaluation of the supply reactions of producers and processors within the agricultural and food markets provides a number of useful results. These supply analyses are very frequently focused on the evaluation of the price-supply elasticity because it is generally assumed that the price of given product itself and prices of related products play the key role in the supply behaviour of firms; see Perloff (1994) or Helmberger and Chavas (1996). Vertical integration of partial markets also needs to be considered when analysing the price-supply functions within the agricultural and food sector as confirmed by the studies on the price transmissions; see Cramer and Jensen (1994) or Bečvářová (2008). This way the impact of input price changes can be evaluated, i.e. impact of changes in the price of raw materials or commodities, labour, energy and land on the supply functions of agricultural commodity producers and processors. In addition to market prices, there are other factors that affect the level of market supply. The market supply is determined by the production conditions in the firms and the competitive environments in the given industry; see Perloff (1994). The supply of agricultural enterprises is primarily determined by the weather conditions and the quality of soil in production areas of particular countries. However, these factors are not crucial for purely foodprocessing firms; see Mundlak et al. (1997).

The competitive environment is very diverse among the partial markets within the agro-food vertical.
A greater number of suppliers associated with stronger competitive environment is usually the case of the agricultural commodity markets. Conversely, the food processing and distributing market is more typically of an oligopolistic market character. The supply reactions of the firms in the agricultural and food sector are obviously strongly affected by the changes in consumer demand for food; see Cramer and Jensen (1994) or Bečvářová (2008). Government interventions in agricultural and food markets are additional supply factors.

Supply of quality wine is strongly influenced by the weather. Favourable weather conditions improve the quantity and quality of the wine grape harvest. The good harvest years increase the market supply and change the market price of wine through demand-supply mechanisms. When it comes to consumption, the sales price of bottled wine is often viewed as an indicator of wine quality. This can be taken as an advantage of wine suppliers. The structure and size of wine market supply in the Czech Republic is also formed by foreign trade. Domestic production covers approximately about one third of annual wine consumption. Thus, import of wine into the Czech Republic exceeds the Czech wine export. The Czech wine export has been decreasing in recent years, and bottled quality wine has prevailed over cask wine when it comes to import.

Aim of this paper is to determine and evaluate the elasticity of the price-supply reactions of the Czech producers of quality bottled white wine. "Quality wine" is a specific category included in the Czech law (similarly to e.g. Slovak, Austrian, German), which 
means, that the wine is produced without an addition of sugar. The price elasticity of given supply will be examined within the Czech wine market from 2004 to 2012. The supply reactions of Czech wine producers will be observed through their realized monthly sales of the quality bottled white wine. Volume of the wine sales will be investigated in relation to the market price of quality bottled wines. This paper will analyse the long-term and short-term price elasticity of studied market supply. The analysis of both categories of price-supply elasticity is based on the log-linear EC model designed and statistically verified by the authors.

\section{MATERIAL AND METHODS}

Data for the evaluation of price sensitivity of the supply of the Czech producers of quality white wine in bottles in the years 2004-2012 were obtained from the Czech Statistical Office (CSO) and State Agricultural Intervention Fund (SAIF). Monthly time series of the prices $\left(P W_{t}\right)$, at which the Czech wine producers sell quality bottled white wine into the shops, restaurants and catering facilities or wine distributors, were obtained from the database of CSO. Thus, $P W_{t}$ does not represent consumer prices, at which households buy the quality bottled white wine. These prices are recorded in CZK per 1 litre. Time series of monthly sales of the Czech producers of quality white wine in bottles $\left(Q W_{t}\right)$ were taken from the SAIF database. Czech producers' monthly sales of quality bottled white wine are recorded in hectolitres. Within the studied period (2004-2012), 108 observations of $P W_{t}$ and $Q W_{t}$ were available for pricesupply analysis, thus $\mathrm{t}=1,2, \ldots, 108$. For distinguishing the given time index $(t)$, the Student test statistic was reported as $t$-statistics in this article. However, the level of prices and sales of the quality bottled white wines were expressed via the logarithms, thus the examining was based on the time series of $\ln P W_{t}$ and $\ln Q W_{t}$, because log-linear specification of model is convenient for elasticity analysis. Through the double log-linear specification of the supply model, it is possible to immediately determine the coefficient of the price-supply responses of wine producers. Time series of $\ln P W_{t}$ and $\ln Q W_{t}$ are shown in Figure 1.

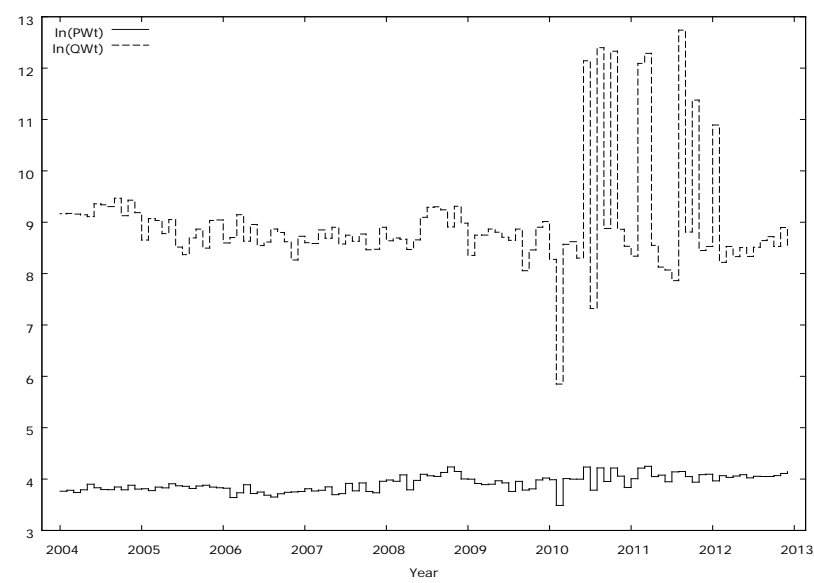

Figure 1 Development of price and sales of quality white wine (calculated by authors)
Stationarity and order of integration of the logarithmically transformed time series of the prices and sales of the quality bottled white wine was studied first; see Engle - Granger (1987). ADF tests were applied for this purpose. The stationarity of $\ln P W_{t}$ and $\ln Q W_{t}$ was not tested around zero, because the market prices of bottled quality white wine and volumes of its sales cannot achieve a negative value.

Within ADF tests of $\ln P W_{t}$ and $\ln Q W_{t}$ the twelve-month lag was considered as theoretical maximum, which is generally recommended for the monthly time series; see e.g. Hušek, (1999). This recommendation regarding the theoretical maximum of time lag was respected within all ADF tests in this article. However, the applied length of lag within autoregressive models for testing of $\ln P W_{t}$ and $\ln Q W_{t}$ time series was reduced in relation to the results of AIC and $t$-tests for each parameter. Based on the ADF test, it was found that the time series of $\ln P W_{t}$ and $\ln Q W_{t}$ are non-stationary, or the presence of a unit root in them could not be rejected at a statistically satisfactory level of significance (5\%). Through the first-order differences, the logarithmic time series of the prices and sales of bottled quality white wines reached stationary development. Time series of $\ln P W_{t}$ and $\ln Q W_{t}$ are thus integrated order one.

After examining the stationarity and integration order of monthly time series of logarithmic prices and sales of bottled quality white wine, a cointegration was analysed. The cointegration of $\ln P W_{t}$ and $\ln Q W_{t}$ was evaluated through Engle and Granger procedure; see Engle - Granger (1987), Arlt (1999) or Hušek (1999). For the evaluation of the long-term and short-term price elasticity of supply of the Czech producers of bottled white quality wine, the Error Correction Model (ECM) was developed and applied. The specification of ECM in terms of lag settings within the considered variables was based on testing various forms of ADL models with one exogenous variable (the price of bottled quality white wine); see Pindyck - Rubinfeld (1998). When selecting a suitable ADL model, there was an emphasis on value of adjusted determination coefficient: $\bar{R}^{2}$, autocorrelation coefficient of the first order: $\rho(1)$, and AIC.

\section{RESULTS AND DISCUSSION}

Based on AIC and t-tests of individual parameters, autoregressive processes in a logarithmic time series of monthly prices of bottled quality white wine $\left(\ln P W_{t}\right)$ can be adequately expressed through the model with the constant and trend with the lag of four months. The estimation of mean value of the parameter $(a-1)$ in this autoregressive model attained the level of -0.318441 , thus $a=0.681559 \pm 0.141393$. Test statistic $\tau$ equalled -2.25217 . The asymptotic significance level of $\tau$-test was $\alpha(\tau)=0.4598$. These results indicate that the presence of a unit root in the logarithmic time series of monthly prices of bottled quality white wine could not be rejected. Other important statistical characteristics of the autoregressive model for time series of $\ln P W_{t}$ were:

a) constant: $\quad c=1.19082 \pm 0.528368 \quad$ with 
$t_{c}=2.254$ and $\alpha\left(t_{c}\right)=0.0265$

b) parameter of linear trend: $b=0.00115026 \pm$ 0.000577860 , with $t_{b}=1.991$ and $\alpha\left(t_{b}\right)=$ 0.0494 ,

c) coefficient of the first order autocorrelation of residues $\rho_{u}(1)=0.024$, and

d) the statistical significance of lag differences $F_{\lambda}(4 ; 96)=4.745 ; \alpha\left(F_{\lambda}\right)=0.0015$.

According to the result of AIC and $t$-tests of individual parameters, autoregressive processes in the logarithmic time series of the monthly sales of bottled quality white wine $\left(\ln Q W_{t}\right)$ could be satisfactorily captured by the model with constant and lag of four months. Mean value of the parameter $(a-1)$ in model of autoregressive process achieved the level -0.5311111 , thus $a=0.468889 \pm 0.202002$. Statistics $\tau$ has the value -2.62924 . The asymptotic significance level of $\tau$ test achieved the value $\alpha(\tau)=0.08701$, i.e. $5 \%<$ $\alpha(\tau)<10 \%$. In line with the determined $\alpha$ level of $\tau$ test, it is not possible to reject the zero value of parameter $(a-1)$ with $95 \%$ probability, but at $90 \%$ level of probability, it is already possible. Subsequently authors considered stationarity of $\ln Q W_{t}$. Other important statistical characteristics of the autoregressive model of $\ln Q W_{t}$ were:

a) constant: $c=4.73603 \pm 1.81138$, where

$t_{c}=2.615$ with $\alpha\left(t_{c}\right)=0.0104$,

b) coefficient of the first order autocorrelation of residues: $\rho_{u}(1)=-0.010$, and

c) the statistical significance of lag differences: $F_{\lambda}(5 ; 95)=4.843 ; \alpha\left(F_{\lambda}\right)=0.0005$.

The principle of ADF tests of unit root was also applied in determining the order of integration of the examined logarithmic monthly time series of prices and sales of bottled quality white wine. For the purpose, the monthly time series were converted to the time series of the first differences of original values: $\Delta \ln P W_{t}$ and $\Delta \ln P W_{t}$. ADF tests of parameter $(a=1)$, i.e. the calculation of $\tau$-statistics and its significance level $\alpha(\tau)$ were then performed on the autoregressive models.

Selection of the most appropriate model of the autoregressive processes in differentiated time series of logarithmic prices and sales was the same as in case of time series of $\ln P W_{t}$ and $\ln Q W_{t}$, i.e. it was based on AIC and $t$-tests for individual parameters. According to results of these criteria, the lag in examined autoregressive model was also adjusted. ADF tests of unit roots in differentiated time series of logarithmic price and sales were, in both case, conducted through autoregressive model without constant and trend. Lag in autoregressive model was set to one month.

The differentiated logarithmic time series of monthly sales and prices of bottled quality white wine showed stationarity around zero. Other important details for this test of stationarity are contained e.g. by Arlt (1999). The estimation of mean value of the parameter $(\alpha-1)$ in this model attained the level of -1.93306 , thus $a=-0.93306 \pm 0.163240$. Test statistics $\tau$ for the parameter $(a-1)$ was $\tau=-11.8419$ and its asymptotic level of statistical significance was $\alpha(\tau)=2.045 *$ $10^{-24}$. The $\tau$-test indicates that the existence of a unit root in $\Delta \ln P W_{t}$ is possible to reject with very high probability. In the autoregressive model with the constant and one-month lag, the autocorrelation coefficient of the first order was equal $\rho_{u}(1)=-0.059$ and estimation of $a_{1}=0.291867 \pm 0.0943452 ; \quad t_{a 1}=3.094 \quad$ and $\alpha\left(t_{a 1}\right)=0.0025$.

In accordance with the results of AIC and $t$-tests, the autoregressive processes in the differentiated time series of logarithmic monthly sales of quality white wine in bottles can be captured by model without constant and with one-month lag. Mean value of the parameter $(\alpha-1)$ in given autoregressive model achieved the level -1.87218 , thus the estimation of $a=-0.87218 \pm$ 0.176024 . Statistics $\tau$ for the $(\alpha-1)$ attained value $\tau=-10.6359$ and its asymptotic level of the statistical significance was $\alpha(\tau)=3.562 * 10^{-21}$. The results of $\tau$ test indicate that the presence of unit root in time series $\Delta \ln Q W_{t}$ could be to reject with very high probability. The autocorrelation coefficient of the first order reaches the value of $\rho_{u}(1)=-0.031$ and the estimation of parameter $a_{1}$ was $0.147890 \pm 0.0974866$ with $t_{a 1}=$ 1.517 and $\alpha\left(t_{a 1}\right)=0.1323$.

From the results of performed ADF tests, the monthly time series of the logarithmic prices and sales of bottled quality white wine appear to be as non-stationary, with $95 \%$ level of probability. Stationarity of the both investigated time series is attainable after the first differencing. After the first-order differences, time series of the logarithmic monthly prices and sales are integrated of the order zero: $\left\{\Delta \ln P W_{t}\right\} \sim \mathrm{I}(0),\left\{\Delta \ln Q W_{t}\right\} \sim \mathrm{I}(0)$. Thus, the non-differenced time series are integrated of order one: $\left\{\ln P W_{t}\right\} \sim \mathrm{I}(1),\left\{\ln Q W_{t}\right\} \sim \mathrm{I}(1)$.

The cointegration of $\ln P W_{t}$ and $\ln Q W_{t}$ was analysed through Engle-Granger procedure (EG test). EG test was used to evaluate the long-term relationship between levels of the prices and sales of bottled quality white wine, i.e. long term supply function on the market for investigated category of wine. Necessary prerequisite for EG test, it is that both time series are non-stationary and integrated of the first order, was confirmed by results of the ADF tests. A cointegration regression, which captures the static shape of the wine processors' supply (law of increasing supply-see Nicholson, 1992) was estimated for the purpose of EG testing procedure. Longterm static supply of the processors of bottled quality white wine was based on the log-linear function without constant (Eq. 1):

$\ln Q W_{t}=B * \ln P W_{t}+r_{t}$.

The residues $r_{t}$ were determined by the cointegration regression (Eq 1). Subsequently, ADF tests of unit root in the time series of residues were performed. Autoregression model without constant and trend was used for these ADF tests of unit root. Lag in this autoregressive model was set in response to results of AIC in combination of $t$-tests of the individual parameters.

After proving cointegration between the monthly time series of logarithmic prices and sales of bottled quality white wine, there was estimated and statistically 
verified the Error Correction Model. Lag setting of the considered variables within ECM was based on testing various forms of ADL models with one exogenous variable - the price of bottled quality white wine. When selecting a suitable ADL model, there was an emphasis on value of $\bar{R}^{2}, \rho(1)$ and AIC. The results of $t$-tests of the individual parameters were taken into account in the selection of the possible specifications of ADL models, too. In this multi-criteria evaluation, ADL model without constant and with one-month lag for the independent and dependent variables (Eq. 2):

$\ln Q W_{t}=3.8381 * \ln P W_{t}-1.6291 * \ln P W_{t-1}+$

$0.03144 * \ln Q W_{t-1}$

The model (Eq. 2) achieved $\bar{R}^{2}=0.9905, \rho(1)=$ 0.03255 and AIC $=279.3028$. $t$-test of the parameter of logarithmic wine price without lag reached $\alpha$-level lower than $0.001 \%\left(1.37 * 10^{-8}\right)$. Based on $t$-test, the parameter of logarithmic wine prices with one-month lag was statistically acceptable at $2.5 \%$ level (0.0244). $t$-test for the parameter of dependent variable with one-month lag was statistically insignificant (0.7505). In accordance with the identification of one-month lag of the independent and dependent variable in the ADL model, structure of ECM was defined (Eq.3):

$\Delta \ln Q W_{t}=\beta * \Delta \ln P W_{t}+\gamma * r_{t-1}+u_{t} ;$

$r_{t-1}=\ln Q W_{t-1}-\mathrm{B} * \ln P W_{t-1}$.

OLS estimates of parameters $\beta$ and $\gamma$ in model (Eq.3) were computed. The standard asymptotic tests can be applied for given OLS estimates, because all the time series used for quantification of model (Eq. 3) are now stationary - see Sims et al. (1990).

The values of parameters obtained within a twostep procedure of ECM estimation, can be interpreted by Engle-Granger (1991) or Arlt (1999) subsequently. Parameter B attained within static cointegration regression is a coefficient of the long-term elasticity of price-supply reactions of the producers of bottled quality white wine. On the contrary, the parameter $\beta$ is a coefficient of the short-term price-supply reactions of the given producers. The parameter $\gamma$ in ECM expressed the intensity of deviation correction of the short-term price-supply reactions from their long-term nature. With that, $\gamma$ correction of given deviation runs in the following month.

Given that the logarithmic time series of the prices and sales of the bottled quality white wine were nonstationary with the first order integration, cointegration regression (Eq. 1) could be estimated. The computed value of parameters of the cointegration regression (Eq. 1) and basic statistical characteristics are depicted in Table 1. From statistical characteristics displayed in Table 1, it is useful to remind that the high level of determination coefficient is caused by the logarithmic transformation of original data and it cannot be overestimated. Within the analysis of cointegration between the logarithmic time series of prices and sales of the bottled quality white wine, the residues $\left(r_{t}\right)$ were determined for each month in observed period 20042012. The investigation of unit root in time series of the time series of residues was carried out again through ADF tests. ADF tests were based on autoregressive model without constant and trend, and with one-month lag (Eq. 4):

$\Delta r_{t}=(a-1) * r_{t-1}+a_{1} * \Delta r_{t-1}+u_{t}$

The lag length in (Eq. 4) was set up again according to the minimum value of AIC and results of the $t$-tests on individual parameters. Based on OLS estimations of the mean values of parameters, the autoregressive model (Eq. 4) can be written as follows: $\Delta r_{t}=-0.700242 * r_{t-1}-0,304082 * \Delta r_{t-1}+u_{t}$. Thus, the estimation of unit root $a$ was equal to $0.299758 \pm 0.133378$. $\tau$-statistics for test of this parameter reached the value -5.25007 . The asymptotic significance level was $\alpha(\tau)=2.211 * 10^{-7}$. The autocorrelation coefficient of the first order in model (4) reached the value of 0.014 .

Table 1 Cointegration regression

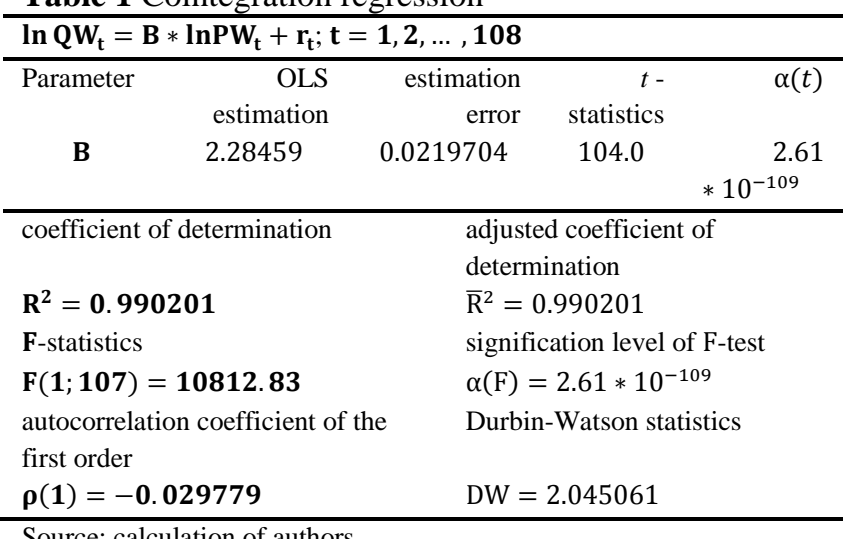

Source: calculation of authors

Results $\tau$-test implied that the null hypothesis of the presence of a unit root in time series of $r_{t}$ can be rejected at relatively high level of probability (more than $1 \%$ ). Thus, we can consider stationarity of the time series of residues or the integration of order zero: $\left\{r_{t}\right\} \sim \mathrm{I}(0)$. In other words, a linear combination of $\ln Q W_{t}$ and $\ln P W_{t}$ gives composite time series that are integrated in the order zero. Logarithmic time series of monthly sales and monthly prices of bottled quality white wine are cointegrated in the order zero with one month lag: $\left\{\ln Q W_{t}\right\} \quad$ and $\quad\left\{\ln P W_{t}\right\} \sim \operatorname{CI}(1 ; 0)$. From an economic point of view, it can be concluded that the volume of monthly sales of the Czech producers of the bottled quality white wine are in a long-term positive relationship with the level of market prices. EGcointegration test confirmed the long-term manifestations of the law of growing supply.

After having proven the cointegration between monthly time series of the price and sales of the bottled quality white wine, Error Correction Model was applied. In accordance with the results of various ADL models that included the white wine price as the only exogenous variable, and based on results of the AIC and of $t$-test on individual parameters, the specification with one-month 
lags of dependent and independent variables was chosen as an appropriate ECM (3): $\Delta \ln Q W_{t}=\beta * \Delta \ln P W_{t}+$ $\gamma * r_{t-1}+u_{t} ; \quad r_{t-1}=\ln Q W_{t-1}-2.28459 * \ln P W_{t-1}$. Achieved estimates of the parameters $\beta$ and $\gamma$ including basic statistical characteristics are displayed in Table 2.

Based upon Table 2, it is obvious that dynamic log-linear model with member for error correction, in specification (Eq. 3):

$\Delta \ln Q W_{\mathrm{t}}=3.83696 * \Delta \ln P W_{t}-0.968774 * r_{t-1}+u_{t}$

shows satisfactory results of the statistical characteristics. The applied ECM (Eq. 3), where error correction is defined as the difference:

$\ln Q W_{t-1}-2.28459 * \ln P W_{t-1}$, can be considered as statistically significant.

In connection with the achieved values of the determination coefficient (Table 2), we can formulate one more important finding, namely that sales of the Czech producers of quality white wine in bottles are approximately in $63 \%$ determined by the level of own price. However, the influence of market price of bottled quality white wine on its sales by producers is distributed into several time periods - see statistically significant one-month lag in ECM.

Table 2 Error Correction Model

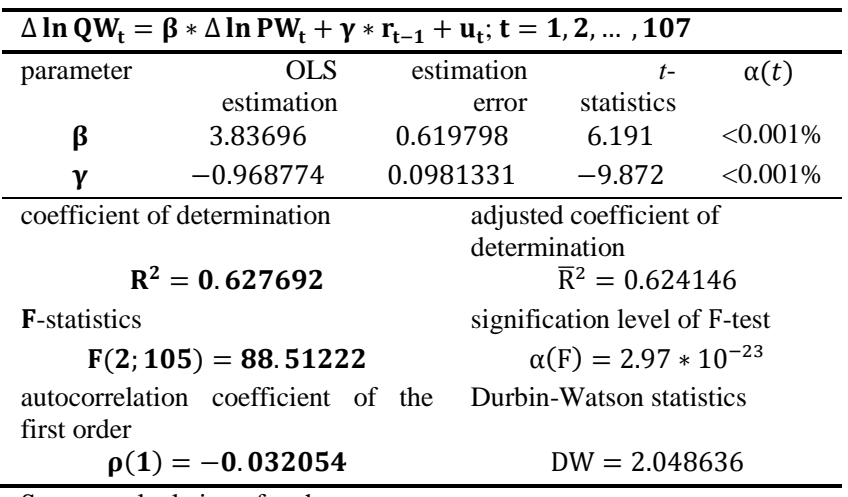

Source: calculation of authors

From the economic point of view, the ECM (3) is also sustainable, because this regression model reflects the law of increasing supply within the long-term and also short-term (immediate) reactions of the Czech producers of the quality white wine in bottles. There is a positive long-term relationship between the monthly sales of the bottled quality white wine and price as shown by the value of $\mathrm{B} ; \mathrm{B}=+2.28459>0$. Parameter $\mathrm{B}$ can also be interpreted as coefficient of long-term price elasticity of market supply of the Czech white wine producers. That means that it determines the percent changes in the Czech producer's supply on the market for the bottled quality white wine, when the market price of the quality white wine goes up by $1 \%$. In accordance with the attained value of the parameter $B$ it can therefore be concluded that the increase in the price per litre of bottled quality white wine by $1 \%$ will bring the market supply growth, which will (in long-term) tend to value $2.28 \%$. Immediate (short-term) reactions of the Czech producers of bottled quality white wine can be demonstrated by the positive value of parameter $\beta$; $\beta=3.83696>0$. The value of $\beta$ parameter can be interpreted as the coefficient of short-term price elasticity of the given market supply. In relation to the value of $\beta$ parameter, it can be maintained that $1 \%$ rise of the market price of bottled quality white wine increases immediately the supply of the Czech producers of quality white wine by $3.84 \%$. Based upon the demonstrated values of the price supply elasticity, we conclude that short-term price-supply reactions of the Czech producers of quality white wine are more elastic than their reactions in long-term period. That can be successfully explained by strengthening the sales of the quality white wine in bottles from producers' inventory. Based upon the parameter $\gamma$, it can be stated that short-term deviations of the price-supply reactions of Czech wine producers from its long-term trend will be diminished in the next month with the intensity of 0.968774 .

The achieved estimates of the price elasticity of market supply of bottled quality white wines must be viewed in relation to the calculated determination index, which reached through the used ECM (3) the levels less than $63 \%$. Thus, market supply of the bottled quality white wine is evidently influenced also by other factors other explanatory variables for ECM. These facts were already indicated in Figure 1, where the sales of bottled quality white wine in some months between 2010 and 2012 dramatically increased without significant growth of the market price. Economic theory suggests an analysis of substitution or complementary effects in market supply, for these purposes, but it is always necessary to perceive the technological context and longterm or short-term constraints for the given production. These conclusions actually open up further research questions and opportunities for further research and analysis in this field. Further research opportunities include examination of simultaneous relationship between $P W_{t}$ and $Q W_{t}$ using VECM instead of oneequation ECM, and also performing a study of the transitory and permanent effects of the supply shocks.

\section{CONCLUSIONS}

This paper focused on price elasticity of market supply of the Czech producers of quality white wine in bottles. The price-supply elasticity was analysed in the years 20042012 through monthly data about price of bottled quality white wine and its sales. Price-supply reactions of the Czech producers of bottled quality white wine were evaluated within short-term and long-term period. The analysis of the price elasticity of market wine supply was based on two-step cointegration method developed by Engle and Granger (1991). The cointegration regression was determined in the first step as well as the coefficient of long-term price supply elasticity -the B parameter. Its value was estimated as 2.28459 , which suggested that if the price of bottled quality white wine had been raised by $1 \%$, the Czech producers would have increased their sales approximately by $2.28 \%$ in the long-term. The cointegration regression was used to construct Error Correction Model in the second step. Based upon 
parameter $\beta$ in the developed ECM, the immediate (short-term) price-supply reactions of the Czech producers of quality white wine in bottles were evaluated. The value of $\beta$ was calculated to be 3.83696 , which suggested that when the price of bottled quality white wine had increased by $1 \%$, the Czech producers immediately increased their sales in this product category by $3.84 \%$. This information provides an interesting issue for further analyses aiming on the availability of stock reserves and the speed of possible reaction of producers and also possible differences in the speed in particular types and qualitative categories of wines.

\section{REFERENCES}

ARLT, J. 1999. Moderní metody modelování ekonomických časových řad. (Modern methods of modelling economic time series). Grada Publishing. ISBN: 80-7169-539-4.

BEČVÁŘOVÁ, V. 2008. Issues of competitiveness of today's agriculture. Agricultural Economics - Czech, 54 (9), 399-405. Available at: http://www.agriculturejournals.cz/publicFiles/02184.p df

CARLTON, D. W. - PERLOFF, J. M. 1994. Modern Industrial Organization. Second Edition. Harper Collins College Publishers. ISBN: 0-673-46902-6.

CRAMER, G. L. - JENSEN, C. W. 1994. Agricultural Economics and Agribusiness. Sixth Edition. John Wiley \& Sons. ISBN: 0-471-59552-7.

ENGLE, R. F. - GRANGER, C. W. J. 1987. CoIntegration and Error Correction: Representation,
Estimation, and Testing. Econometrica, 55 (2), 251-276. doi: http://dx.doi.org/10.2307/1913236

ENGLE, R. F. - GRANGER, C. W. J. 1991. Long Run Economic Relationships: Readings in Cointegration. First Edition. Oxford University Press. ISBN: 978-0-19828339-3

HELMBERGER, P. G. - CHAVAS, J. P. 1996. The Economics of Agricultural Prices. Prentice Hall. ISBN 013-372640-1

HUŠEK, R. 1999. Ekonometrická analýza (Econometric analysis). Ekopress. ISBN 80-86119-19-X.

MUNDLAK, Y. - LARSON, D. F. - BUTZER, R. 1997. The Determinants of Agricultural Production: A CrossCountry Analysis. Policy Research Working Paper, Series 1827, The World Bank. Available at: http://wwwwds.worldbank.org/servlet/WDSContentServer/WDSP/I B/2000/02/24/000009265_3971110141412/Rendered/PD F/multi_page.pdf

NICHOLSON, W. 1992. Microeconomic Theory, Basic Principles and Extensions. Fifth Edition. Dryden Press. ISBN: 0-030-75391-0

PINDYCK, R. S.-RUBINFELD, D. L. 1998. Econometric Models and Economic Forecasting. Fourth Edition. Irwin/McGraw-Hill. ISBN: 0-070-50208-0

SIMS, C. A. - STOCK, J. H. - WATSON, M. W. 1990. Inference in Linear Time Series Models with Some Unit Roots. Econometrica, $58 \quad$ (1), 113-144. doi: http://dx.doi.org/10.2307/2938337 